\title{
Fading Due the Unfading: Repeated Anaphylaxis Caused by Amaranth Grains
}

Claudia Pföhler*, Andreas Merkoureas, Cornelia SL Müller and Thomas Vogt

Department of Dermatology, Saarland University Medical School, Homburg/Saar, Germany

*Corresponding author: Claudia Pföhler, Saarland University Medical School, Department of Dermatology, 66421, Homburg/Saar Germany, Tel: +49(0)6841-16-23840 Fax: +49-(0)6841-16-23842; Email: claudia.pfoehler@uks.eu

Received: January 29, 2015; Accepted: March 14, 2015; Published: March 23, 2015

Copyright: (C2015 Pföhler C, et al. This is an open-access article distributed under the terms of the Creative Commons Attribution License, which permits unrestricted use, distribution, and reproduction in any medium, provided the original author and source are credited.

\begin{abstract}
s
Food allergy is one of the most frequently reported causes for anaphylactic reactions. Most cases are caused by tree nuts, peanuts, fish, shellfish, milk, eggs or soy. We present a 43-year old female patient who developed two anaphylactic episodes after consumption of a self-mixed cereal including oatmeal, fresh milk, strawberries, apples and amaranth grains. Toasted amaranth grains could be identified as elicitor of anaphylaxis by prick-to-prick testing. Amaranth grains are a very uncommon elicitor of anaphylaxis, however amaranth should be kept in mind as a cause for food allergy as the consumption of this product is rising.
\end{abstract}

Keywords: Allergy; Anaphylactic reactions; Amaranth grains; Food allergy

\section{Introduction}

Food allergy is an immunological reaction against a food allergen and represents the leading cause of anaphylaxis treated in hospital emergency departments in Western Europe and the United States [1]. With a prevalence of $4 \%-8 \%$ in children and $4 \%$ in adults food allergy is a common health problem since two thousand years. Hippocrates, the ancient Greek physician, described a reaction to milk in the $1^{\text {st }}$ century [1]. Elicitors of food allergies vary significantly across different countries. Most reactions are caused by milk, eggs, wheat, peanuts and soybeans $[1,2]$. Immunologically, food allergies are classified in IgEmediated, cell-mediated or mixed IgE- and cell-mediated reactions [2] The typical IgE-mediated food allergy manifests with the signs and symptoms of an anaphylaxis (urticaria, angioedema, hypotension, bronchospasm, cardiovascular und respiratory shock). Detection of the elicitor is the challenge for treating physicians. Food allergen elimination from the diet is the only proven therapy [1]

\section{Case Report}

A 43-year old female patient was referred to our clinic for further investigation of two episodes of anaphylaxis that she had developed after breakfast in the recent past. Anaphylactic symptoms occurred 20 minutes after consumption of a cereal containing lactose-free milk, oat flakes, roasted amaranth grains, fresh apples and strawberries. She had been eating breakfast in this composition for several months. In both cases, the patient developed an urticarial rash, tongue-swelling, dyspnea and a cardiovascular collapse and needed to be treated with corticosteroids and antihistamines from an emergency physician.

She reported mild symptoms of pollinosis in spring and summer since several years but denied ever suffering from asthma or atopic eczema.

Blood analysis showed normal values for basal serum tryptase and total IgE (tryptase: $3.34 \mu \mathrm{g} / \mathrm{l}$, total IgE: $37 \mathrm{U} / \mathrm{ml}$ ). Specific IgE serum antibodies against wheat flour, rye flour, oat flakes, buckwheat flour, japanese millet, foxtail millet, rice, broomcorn millet, sesame, strawberry and Mal d3 were negative. Specific IgE antibodies against green apple $(0.73 \mathrm{k} \mu / \mathrm{l}$, CAP class 2$)$ and peach $(0.40 \mathrm{k} \mu / \mathrm{l}$, CAP class 1$)$ were slightly elevated. Specific IgE antibodies for grass pollen $(0.37$ $\mathrm{k} \mu / \mathrm{l}, \mathrm{CAP}$ class 1$)$ and tree pollen $(2.56 \mathrm{k} \mu / \mathrm{l}$, CAP class 2) were positive.

Skin prick testing included grass, tree and weed pollen, molds, dust and storage mites, ragweed, cat epithelia, wheat corn, egg, cow milk, celery root, cod, hazelnut and almond (All test solutions from Bencard allergies $\mathrm{GmbH}$, Munich, Germany) Reading was performed after twenty minutes and showed positive reactions for grass, tree and weed pollen, all other substances were negative.

Prick-to-prick testing with wheat and rye flour, lactose free low fat milk, fresh apple, oat flakes and toasted amaranth grains showed a histamine equivalent reaction against amaranth grains (Figure 1). For prick-to prick testing a teaspoon of every natural food was minced in a porcelain mortar and $5 \mathrm{ml}$ of $0.9 \%$ sodium chloride solution was added. Prick-to-prick testing was performed with this mixture.

An oral food challenge was planned to finally confirm the diagnosis, but the patient declined to perform this procedure.

Conclusively we diagnosed a repeated anaphylactic reaction grade 3 resulting from a sensitization against amaranth grains.

\section{Discussion}

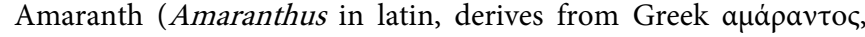
that means unfading flower) is a cosmopolitan genus of annual or short-lived perennial plants. Some amaranth species are cultivated as leaf vegetables, cereals, and ornamental plants [3]. Amaranth grains are consumed as substitute to cereals by people in India or Iran (with the name Rajgira or Ramdana) during fasting periods [4]. To this day, amaranth grains are toasted much like popcorn and mixed with honey, molasses or chocolate or are added in cereal mixtures.

Type I sensitization with the clinical manifestation of an allergic rhinoconjuctivitis caused by pollen of Amaranthus spinosus and Amaranthus retroflexus has been reported by several authors $[5,6]$. In 2013 the first case of an anaphylactic reaction after consumption of amaranth grains has been published [4]. This allergy therefore seems 
Citation: Pföhler C, Merkoureas A, Müller C, Vogt T (2015) Fading Due the Unfading: Repeated Anaphylaxis Caused by Amaranth Grains. J

Page 2 of 2

to be very rare. Little is known about the allergenic potential of amaranth grains. Kasera and coworkers could identify 16 IgE-binding fractions from raw and roasted amaranth extracts [4]. Cross-reactive allergenic components in the pollen among the different amaranth species exist, however knowledge concerning this allergy is limited $[4,6]$. As the addition of amaranth to different cereals is increasing as a kind of fashion trend in nutrition, amaranth allergy should be kept in mind as a possible elicitor of anaphylaxis.

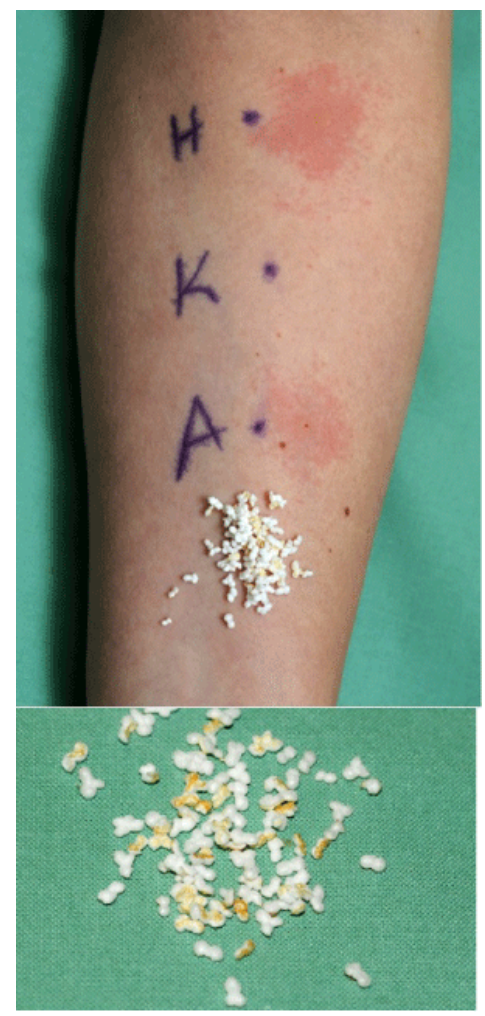

Figure 1: Positive prick-to-prick test with roasted amaranth grains from the cereal. A) A, popped amaranth grains in aqua ad iniectabilia; $\mathrm{H}, 1.0 \%$ histamine solution (Bencard Allergie $\mathrm{GmbH}$, Munich, Germany) served as positive control; K, sodium chloride solution $0.9 \%$ served as negative control). Reading of the test was performed after 20 minutes. B) Popped amaranth grains in detail.

\section{References}

1. Cianferoni A, Spergel JM (2009) Food allergy: Review, classification and diagnosis. Allergology International 58: 457-466.

2. Sampson HA (2003) Food allergy. Journal of Allergy and Clinical Immunology 111: 540-546.

3. Bensch CN, Horak MJ, Peterson D (2003) Interference of redroot pigweed (Amaranthus retroflexus), Palmer amaranth (A. palmeri), and common waterhemp (A. rudis) in soybean. Weed Science 51: 37-43.

4. Kasera R, Niphadkar PV, Saran A, Mathur C, Singh AB (2013) First case report of anaphylaxis caused by Rajgira seed flour (Amaranthus paniculatus) from India: A clinico-immunologic evaluation. Asian Pacific Journal of Allergy and Immunology 31: 79-83.

5. Tehrani M, Sankian M, Assarehzadegan MA, Falak R, Noorbakhsh R, et al. (2011) Identification of a new allergen from Amaranthus retroflexus Pollen, Ama r2. Allergology International 60: 309-316.

6. Tehrani M, Sankian M, Assarehzadegan MA, Falak R, Noorbakhsh R, et al. (2010) Immunochemical characterization of Amaranthus retroflexus pollen extract: extensive cross-reactive allergenic components among the four species of Amaranthaceae/Chenopodiaceae. Iranian Journal of Allergy, Asthma and Immonology 9: 87-95. 